\title{
Work in Progress: Crossing the Engineering Border into Art and Society with a Materials Selection for the Life Cycle course
}

\author{
Katherine C. Chen and Blair London \\ Materials Engineering, California Polytechnic State University \\ San Luis Obispo, CA 93407 \\ kcchen@calpoly.edu, blondon@calpoly.edu
}

\begin{abstract}
A new course in materials engineering has been developed to incorporate industrial design and sustainability principles. Many current engineering tasks require the ability to comprehend and consider the complicated interplay of technology with the environment and society. Thus the changing skill set required of future engineers is being reflected in the changes with our courses. We are stepping beyond the traditional boundaries of engineering courses to present a more holistic approach to problem solving. The use of materials and processing techniques is applied to product design, and thus involves consideration of the end user and the end of product life. Green engineering and cradle to cradle design principles are also introduced in the course. Outcomes for this class include students being able to employ systems thinking, to formulate creative design solutions, and to select the appropriate materials and processing for minimal environmental impact.
\end{abstract}

Index Terms - green engineering, materials selection, sustainability, systems thinking

\section{SYSTEMS THINKING}

A new course in the sophomore series of the Materials Engineering curriculum at Cal Poly, San Luis Obispo was recently piloted and is currently undergoing revisions. The course is entitled, "Materials Selection for the Life Cycle," and comes after the introductory course in materials (which also serves as the service course to other engineering disciplines). In the past, our materials engineering students first delved into smaller dimensions and were immersed into the exhaustive details of atomic arrangements and crystallographic imperfections of materials. Our new approach is to begin with the opposite direction of looking at the bigger picture - How do materials interface with society and the environment? We still try to connect material properties to crystallographic structures, but now attempt to cover larger and more pertinent issues within meaningful contexts.

The educational training for future engineers has been recently shifting in response to the Accreditation Board of Engineering and Technology (ABET) and the proposed Engineer for the year 2020 by the National Academy [1]. 1-4244-0257-3/06/\$20.00 @ 2006 IEEE
ABET requires programs to train students to solve problems and design within realistic design constraints that include sustainability. Accordingly, our curriculum is currently being revised to nurture more global, effective materials engineers for the future [2], and this particular class is just one part of the whole curriculum reform. By venturing out of the confines of our discipline and connecting to other fields, we hope to produce more well-rounded engineers that can see how engineering is connected to society and the environment.

\section{INDUSTRIAL DESIGN}

We cross the borders of traditional engineering, and enter into the worlds of art, industrial design, business, and communication. Using the book, "Materials and Design: The Art and Science of Material Selection in Product Design" by Ashby and Johnson [3], materials are presented as more of a means, rather than the end. The focus shifts to the consumer and the desired end product. Many colorful pictures and numerous, relevant examples are given in the book. Functional and design requirements are established before the appropriate material is selected. The human element must also be considered, and the reactions to the senses (such as touch, color, shape) become properties dependent upon choice of materials, similar to thermal conductivity or strength.

Students are more engaged when they can associate concepts to actual applications and relevant examples. For instance, various material properties are discussed with examples of different water containers or kitchen utensils. Critical thinking and creativity are also encouraged when exploring marketing techniques and new design opportunities with the development of new materials.

\section{Sustainability Principles}

An additional materials selection criterion that is emphasized in this course is the impact on the environment. The Brundtland Commission has defined sustainability [4] as "development that meets the needs of the present without compromising the ability of future generations to meet their own needs." To present a holistic view of engineering, we deliberately chose to present life cycle analysis and systems thinking early in our curriculum. The choices of materials and processing techniques intimately affect the entire life cycle of

October 28 - 31, 2006, San Diego, CA 
Session S4H

a product in terms of energy use and impact on the environment. CES eco-selector software [5] is employed to quantitatively assess energy use and identify the life cycle stage that has the largest impact (e.g., extraction, manufacturing, transportation, use, and disposal). By identifying the life cycle stage with the largest energy use or largest environmental impact, one can then offer effective solutions for improvements. Environmental stressors and impacts are also identified with particular processes and products.

Numerous articles are assigned to showcase innovative designs and creative solutions. Examples, such as the Steelcase Think chair [6] and Interface carpeting [7], vividly illustrate green engineering and cradle to cradle design principles $[8,9]$. The readings show how materials can play a large role in sustainable product design. Assignments include finding and describing current "green" products and also identifying products, companies, or processes that could be targeted for significant improvements.

\section{Project AND ASSESSMENT}

The class culminates in a poster session of team projects, where the goal was to devise a "new and improved" product (with less impact on the environment) that could be pitched to capital venture firms. The project encourages students to be creative and innovative with their new product. Design principles introduced in the class can now be implemented. Energy use at each life cycle stage is to be considered. A life cycle inventory and identification of environmental stressors is required for the existing product and their new proposed product. Figure 1 shows an example of one of the projects.

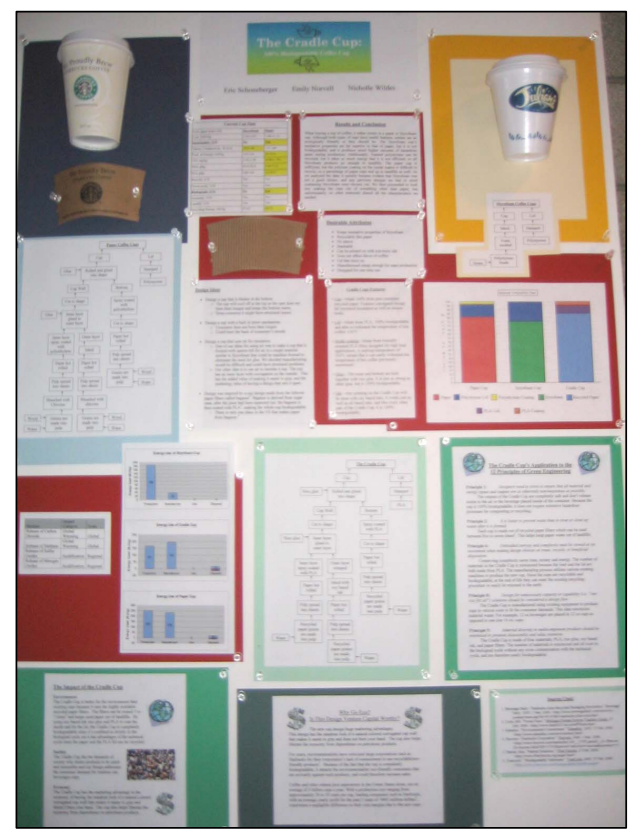

FIGURE 1

Award-Winning Poster of Team Term Project of "The Cradle CuP" THAT INCLUDES LIFE CYCLE ANALYSIS, IMPROVED MATERIAL PROPERTIES, SUSTAINABILITY PRINCIPLES, AND MARKETING FEATURES.

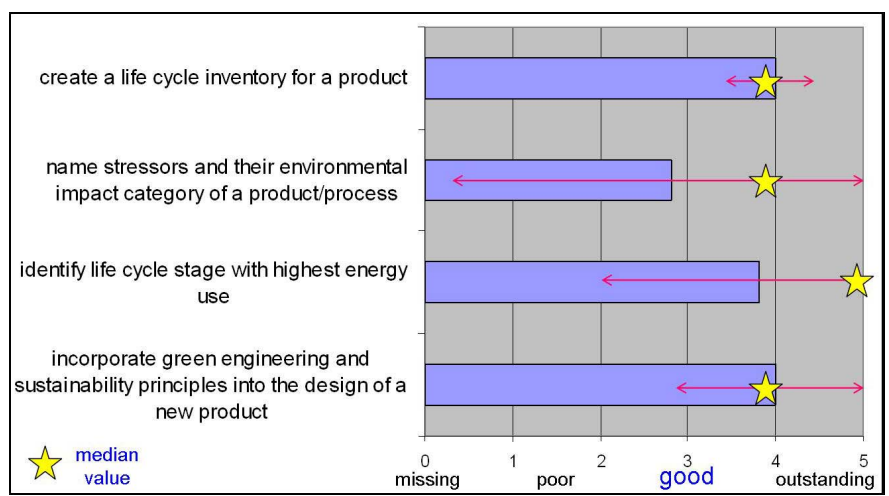

FIGURE 2

AsSessment of Average, Standard DeViation, AND MEdian SCore For TEAM PROJECT ITEMS AND COURSE OUTCOMES

Some students were excited by the challenge, while others were uncomfortable that there was no single correct answer. The student teams took pride in their projects and were eager to present their poster to others. Outside judges are solicited, and prizes are given to the best posters.

Students are given specific evaluation criteria (i.e., presentation features and analysis items) that also map to our desired outcomes for the course. The criteria are used by the students to guide their project, as well as for the instructors to use in their grading. Scores of 0-5 are assigned for each item. A score of " 3 " is considered "good" and signifies that the team met our minimum expectation. A " 5 " is "outstanding," and a " 0 " means that the item is nonexistent or incorrect. Figure 2 shows the mean, standard deviation, and median score for 4 of the evaluation items for all 11 teams. Overall, we were quite successful in that most of the teams appear to be able to implement most of the concepts and tools covered in the course. The assessment also identifies areas in which we need to spend more time in class, provide more feedback, or develop better assignments for future iterations of the course.

\section{ACKNOWLEDGMENT}

This work was supported in part by a grant from the National Science Foundation (Grant\#EEC-0530760).

\section{REFERENCES}

[1] National Academy of Engineering, The Engineer of 2020: Visions of Engineering in the New Century, (The National Academies Press, 2004).

[2] Chen, K., L. Vanasupa, B. London, and R. Savage, "Infusing the Materials Engineering Curriculum with Sustainability Principles," Proceedings of the 2006 ASEE Annual Conference.

[3] Ashby, M. and Johnson, K., Materials and Design: The Art and Science of Material Selection in Product Design, Butterworth-Heinemann, 2002.

[4] www.sustainablemeasures.com/Training/Indicators/Def-Br1.html

[5] www.grantadesign.com/products/mi/ecoselector.htm

[6] www.steelcase.com/na/products.aspx?f $=11845 \& \mathrm{c}=17820$

[7] www.interfaceinc.com/goals/sustainability overview.html

[8] McDonough, W., M. Braungart, P. Anastas, and J. Zimmerman, "Applying the Principles of Green Engineering to Cradle-to-Cradle Design," Environmental Science \& Technology, Dec. 2003: 434 A.

[9] McDonough, W. and M. Braungart, Cradle to Cradle: Remaking the Way We Make Things, North Point Press, 2002. 